\title{
Theranostic Perspectives in Prostate Cancer with the Gastrin- Releasing Peptide Receptor Antagonist NeoBOMB1: Preclinical and First Clinical Results
}

\author{
Berthold A. Nock ${ }^{1}$, Aikaterini Kaloudi ${ }^{1}$, Emmanouil Lymperis ${ }^{1}$, Athina Giarika ${ }^{1}$, Harshad R. Kulkarni ${ }^{2}$, Ingo Klette ${ }^{2}$, \\ Aviral Singh ${ }^{2}$, Eric P. Krenning ${ }^{3}$, Marion de Jong ${ }^{3,4}$, Theodosia Maina ${ }^{1}$, and Richard P. Baum ${ }^{2}$ \\ ${ }^{I}$ Molecular Radiopharmacy, INRASTES, National Center for Scientific Research "Demokritos", Athens, Greece; ${ }^{2}$ Theranostics \\ Center for Molecular Radiotherapy and Molecular Imaging, Zentralklinik, Bad Berka, Germany; ${ }^{3}$ Department of Nuclear Medicine, \\ Erasmus MC, Rotterdam, The Netherlands; and ${ }^{4}$ Department of Radiology, Erasmus MC, Rotterdam, The Netherlands
}

We recently introduced the potent gastrin-releasing peptide receptor (GRPR) antagonist ${ }^{68} \mathrm{Ga}-\mathrm{SB} 3\left({ }^{68} \mathrm{Ga}\right.$-DOTA- $p$-aminomethylaniline-diglycolic acid-DPhe-Gln-Trp-Ala-Val-Gly-His-Leu-NHEt), showing excellent tumor localizing efficacy in animal models and in patients. By replacement of the C-terminal Leu ${ }^{13}-\mathrm{Met}^{14}-\mathrm{NH}_{2}$ dipeptide of SB3 by $\mathrm{Sta}^{13}-\mathrm{Leu}^{14}-\mathrm{NH}_{2}$, the novel GRPR antagonist NeoBOMB1 was generated and labeled with different radiometals for theranostic use. We herein report on the biologic profile of resulting ${ }^{67 / 68} \mathrm{Ga}-,{ }^{111} \mathrm{In}$-, and ${ }^{177} \mathrm{Lu}-\mathrm{NeoBOMB} 1$ radioligands in GRPR-expressing cells and mouse models. The first evidence of prostate cancer lesion visualization in men using ${ }^{68} \mathrm{Ga}-\mathrm{NeoBOMB} 1$ and PET/CT is also presented. Methods: NeoBOMB1 was radiolabeled with ${ }^{67 / 68} \mathrm{Ga},{ }^{111} \mathrm{In}$, and ${ }^{177} \mathrm{Lu}$ according to published protocols. The respective metalated species ${ }^{\text {nat }} \mathrm{Ga}-$, natIn-, and natLu-NeoBOMB1 were also synthesized and used in competition binding experiments against $\left[{ }^{125} /-\mathrm{Ty}^{4}\right] \mathrm{BBN}$ in GRPRpositive PC-3 cell membranes. Internalization of ${ }^{67} \mathrm{Ga}-,{ }^{111} \mathrm{In}-$, and ${ }^{177} \mathrm{Lu}-\mathrm{NeoBOMB} 1$ radioligands was studied in PC-3 cells at $37^{\circ} \mathrm{C}$, and their metabolic stability in peripheral mouse blood was determined by high-performance liquid chromatography analysis of blood samples. Biodistribution was performed by injecting a ${ }^{67} \mathrm{Ga}-,{ }^{111} \mathrm{In}-$, or ${ }^{177}$ Lu-NeoBOMB1 bolus $(74,74$, or $370 \mathrm{kBq}$, respectively, $100 \mu \mathrm{L}, 10$

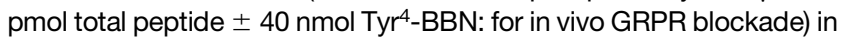
severe combined immunodeficiency mice bearing PC-3 xenografts.

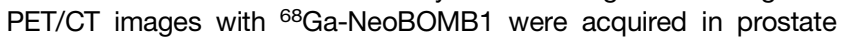
cancer patients. Results: NeoBOMB1 and natGa-, nat/n-, and natLuNeoBOMB1 bound to GRPR with high affinity (half maximal inhibitory concentration, 1-2 nM). ${ }^{67} \mathrm{Ga}-,{ }^{111} \mathrm{In}-$, and ${ }^{177} \mathrm{Lu}-\mathrm{NeoBOMB} 1$ specifically and strongly bound on the cell membrane of PC-3 cells displaying low internalization, as expected for receptor antagonists. They showed excellent metabolic stability in peripheral mouse blood $(>95 \%$ intact at $5 \mathrm{~min}$ after injection). After injection in mice, all 3 ( ${ }^{67} \mathrm{Ga}-,{ }^{111} \mathrm{In}-$, and $\left.{ }^{177} \mathrm{Lu}-\mathrm{NeoBOMB} 1\right)$ showed comparably high and GRPR-specific uptake in the PC-3 xenografts (e.g., $30.6 \pm 3.9,28.6 \pm$ 6.0 , and $>35$ percentage injected dose per gram at $4 \mathrm{~h}$ after injection, respectively), clearing from background predominantly via the kidneys. During a translational study in prostate cancer patients, ${ }^{68} \mathrm{Ga}-\mathrm{NeoBOMB} 1$ rapidly localized in pathologic lesions, achieving high-contrast imaging. Conclusion: The GRPR antagonist radioligands ${ }^{67} \mathrm{Ga}-,{ }^{111} \mathrm{In}-$, and ${ }^{177} \mathrm{Lu}-\mathrm{NeoBOMB} 1$, independent of the radiometal applied, have shown comparable behavior in prostate

Received May 28, 2016; revision accepted Jul. 13, 2016.

For correspondence or reprints contact: Berthold A. Nock, Molecular Radiopharmacy, INRASTES, NCSR "Demokritos", Ag. Paraskevi Attikis, GR-15310 Athens, Greece.

E-mail: nock_berthold.a@hotmail.com

Published online Aug. 4, 2016.

COPYRIGHT (C) 2017 by the Society of Nuclear Medicine and Molecular Imaging. cancer models, in favor of future theranostic use in GRPR-positive cancer patients. Such translational prospects were further supported by the successful visualization of prostate cancer lesions in men using ${ }^{68} \mathrm{Ga}-\mathrm{NeoBOMB} 1$ and PET/CT.

Key Words: molecular tumor imaging; PET; SPECT; radionuclide therapy; theranostic applications; prostate cancer; gastrin releasing peptide receptor antagonist

J Nucl Med 2017; 58:75-80

DOI: 10.2967/jnumed.116.178889

$\mathbf{T}$ he high-density expression of gastrin-releasing peptide receptors (GRPRs) in frequently occurring human cancers, such as prostate cancer and mammary carcinoma, compared with their lack of expression in surrounding healthy tissue provides valid opportunities for molecular imaging and internal radiotherapy with peptide radioligands (1-O). The first-generation radiopeptides developed for such purposes were GRPR agonists derived from C-terminal fragments of the amphibian tetradecapeptide bombesin (BBN) (7-12) or the respective human 27 mer peptide GRP (13-15). The use of resulting radioligands in humans was soon linked to undesirable effects after agonist-induced GRPR activation (16). This finding limited the translational prospects of radioagonists despite their ability to internalize in cancer cells, a property considered at first essential for good diagnostic sensitivity and therapeutic efficacy.

This notion has drastically changed with the advent of the secondgeneration GRPR radiotracers, which were instead based on GRPR antagonists $(17,18)$. Several studies have shown that noninternalizing radioantagonists can successfully target and be sufficiently retained in GRPR-expressing cancer lesions while rapidly clearing from physiologic organs in both animal models and humans. The superior pharmacokinetics of GRPR radioantagonists over their agonist counterparts in combination with their higher inherent biosafety has shifted current research toward the design of new improved GRPR radioantagonist candidates with clear potential for clinical translation (19-23).

Following this rationale, we have initially developed ${ }^{99 \mathrm{~m} T c-}$ demobesin 1 ( $\left.{ }^{99 \mathrm{~m}} \mathrm{Tc}-\mathrm{DB} 1\right)$, a GRPR antagonist radioligand for SPECT imaging, labeled with ${ }^{99 \mathrm{~m}} \mathrm{Tc}$ and containing the [DPhe ${ }^{6}$, Leu-NHEt ${ }^{13}$,des-Met $\left.{ }^{14}\right] \mathrm{BBN}(6-14)$ peptide fragment $(17,18)$. To allow labeling with other clinically relevant radiometals, we then replaced the acyclic tetraamine chelator of DB1 by the universal 
chelator DOTA. The resulting peptide-conjugate SB3 was labeled with ${ }^{68} \mathrm{Ga}$ and evaluated as a PET tracer first in animals and eventually in patients with prostate and breast cancer (23). Interestingly, the respective ${ }^{111} \mathrm{In}$ - and ${ }^{177} \mathrm{Lu}$-labeled radioligands, in addition to showing less affinity for GRPR, turned out to be less stable in the biologic milieu. As a result, GRPR targeting of xenografts in animal models in the case of ${ }^{111} \mathrm{In}$ - and ${ }^{177} \mathrm{Lu}-\mathrm{SB} 3$ was found inferior to ${ }^{68} \mathrm{Ga}-$ SB3, restricting the theranostic application options of SB3 in the clinic (24).

Truncation of C-terminal Met ${ }^{14}-\mathrm{NH}_{2}$ and alkylation of the $\mathrm{Leu}^{13} \mathrm{NH}_{2}$ amide is only one of many $\mathrm{C}$-terminus modifications in the $\mathrm{BBN}(6-14)$ motif, shown to convey antagonistic properties to resulting receptor ligands. For example, replacement of the C-terminal Leu ${ }^{13}-\mathrm{Met}^{14}-\mathrm{NH}_{2}$ dipeptide by $\mathrm{Sta}^{13}-\mathrm{Leu}^{14}-\mathrm{NH}_{2}$ and coupling of DOTA has recently fostered the development of promising GRPR radioantagonists $(20,21,25)$. We have shown though that such a GRPR radioantagonist, $\left[{ }^{68} \mathrm{Ga} /{ }^{177} \mathrm{Lu}\right] J M V 4168$, can reach its full theranostic potential only after injection of phosphoramidon (22). The latter, by in situ inhibition of the catabolic action of neutral endopeptidase, increased the stability of $\left[{ }^{68} \mathrm{Ga} /{ }^{177} \mathrm{Lu}\right] J M V 4168$ in peripheral blood, leading to notably enhanced tumor uptake. This study has highlighted the importance of in vivo stability for the success of GRPRsupported tumor targeting.

In the quest of radioligands with higher stability, our attention was attracted by the improved stability, and potency, reported for the well-characterized GRPR antagonist Ac-His-Trp-Ala-Val-GlyHis- $\mathrm{NH}-\mathrm{CH}\left[\mathrm{CH}_{2}-\mathrm{CH}\left(\mathrm{CH}_{3}\right)_{2}\right]_{2}$ (26). By replacing the C-terminal -His ${ }^{12}-\mathrm{Leu}^{13} \mathrm{NHEt}$ of SB3 by $-\mathrm{His}^{12}-\mathrm{NH}-\mathrm{CH}\left[\mathrm{CH}_{2}-\mathrm{CH}\left(\mathrm{CH}_{3}\right)_{2}\right]_{2}$, we produced NeoBOMB1, which we labeled with ${ }^{68} \mathrm{Ga}$ (for PET), ${ }^{111} \mathrm{In}$ (for SPECT), and ${ }^{177} \mathrm{Lu}$ (for radionuclide therapy). The effect of radiometal on the biologic properties of forming radioligands (Fig. 1), especially on GRPR affinity and in vivo stability, was thoroughly investigated in cell and animal models to assess the theranostic prospects of NeoBOMB1. First translational evidence of the ${ }^{68} \mathrm{Ga}$-NeoBOMB1 efficacy as a PET tracer was acquired in prostate cancer patients using $\mathrm{PET} / \mathrm{CT}$.

\section{MATERIALS AND METHODS}

\section{Ligands and Radioligands}

NeoBOMB1 was provided free by NCSR "Demokritos," and Tyr ${ }^{4}$ BBN was purchased from PSL GmbH. Radiolabeling of NeoBOMB1 with ${ }^{67 / 68} \mathrm{Ga}$, ${ }^{111} \mathrm{In}$, and ${ }^{177} \mathrm{Lu}$ and subsequent quality control were performed as detailed in the supplemental material (available at http://jnm.snmjournals.org). Metalation of NeoBOMB1 with ${ }^{\text {nat }} \mathrm{Ga}$, nat In, and nat $\mathrm{Lu}$ used in in vitro assays is also described therein, along with radioiodination of $\mathrm{Tyr}^{4}-\mathrm{BBN}$ with ${ }^{125} \mathrm{I}$.

\section{In Vitro Assays}

Human androgen-independent prostate adenocarcinoma PC-3 cells expressing the GRPR (LGC Promochem) cultured as previously reported

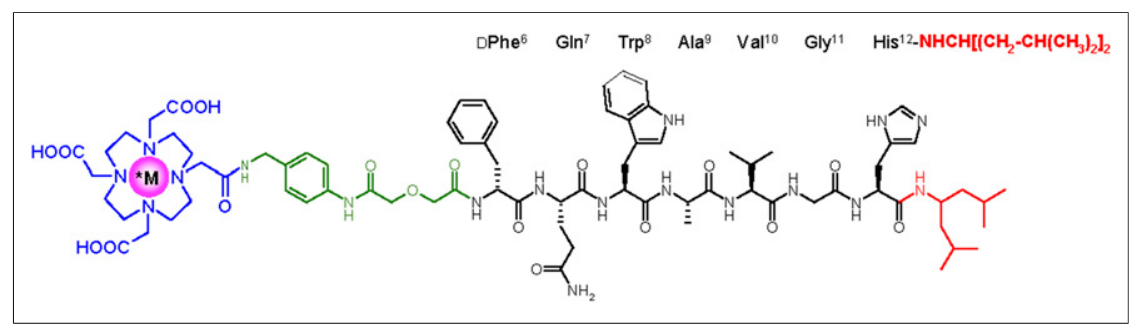

FIGURE 1. Chemical structure of ${ }^{*} \mathrm{M}-\mathrm{NeoBOMB} 1,{ }^{*} \mathrm{M}={ }^{67 / 68} \mathrm{Ga},{ }^{111} \mathrm{In}$, and ${ }^{177} \mathrm{Lu}$. were used in biologic assays $(10,27)$. Competition binding experiments were conducted by incubation of the $\left[{ }^{125} \mathrm{I}_{-} \mathrm{Tyr}^{4}\right] \mathrm{BBN}$ radioligand $(50 \mathrm{pM}$, $\sim 40,000 \mathrm{cpm}$ per assay tube) with increasing concentrations of either test peptide (NeoBOMB1, ${ }^{\text {nat }} \mathrm{Ga}-\mathrm{NeoBOMB} 1$, ${ }^{\text {nat In-NeoBOMB1, or }}$ nat Lu-NeoBOMB1) or reference $\left(\mathrm{Tyr}^{4}-\mathrm{BBN}\right)$ in PC-3 cell membrane homogenates at $22^{\circ} \mathrm{C}$ for $1 \mathrm{~h}$, as previously described $(21,23)$. Filter samples were measured for radioactivity in an automatic well-type $\gamma$-counter $(\mathrm{NaI}(\mathrm{Tl})$ crystal, Canberra Packard Auto- $\gamma$-5000 series instrument). Half maximal inhibitory concentration $\left(\mathrm{IC}_{50}\right)$ values were determined by nonlinear regression according to a 1-site model applying the PRISM 2 program (GraphPad Software) and represent mean \pm SD from 3 independent experiments performed in triplicate.

For cell-binding assays, confluent PC-3 cells were seeded in 6-well plates $\left(\sim 1.2 \times 10^{6}\right.$ cells per well $) 24 \mathrm{~h}$ before the experiment. Test peptide $\left({ }^{67} \mathrm{Ga}-\mathrm{NeoBOMB} 1,{ }^{111} \mathrm{In}-\mathrm{NeoBOMB} 1\right.$, or ${ }^{177} \mathrm{Lu}-\mathrm{NeoBOMB} 1$ [250 fmol total peptide in $150 \mu \mathrm{L}$ of $0.5 \%$ bovine serum albumin/ phosphate-buffered saline]) was added alone (total) or in the presence of $1 \mu \mathrm{M} \mathrm{Tyr}{ }^{4}$-BBN (nonspecific), and the experiment was performed following a published protocol $(21,23)$. Results were calculated as percentage specific and nonspecific internalized plus membrane-bound of total added activity applying the Microsoft Excel program and represent the mean \pm SD of 4 experiments performed in triplicate.

\section{Radioligand Stability and Biodistribution in PC-3 Xenograft- Bearing Mice}

For metabolic studies in mice, each radioligand $\left({ }^{67} \mathrm{Ga}-\mathrm{NeoBOMB} 1\right.$, ${ }^{111}$ In-NeoBOMB1， or $\left.{ }^{177} \mathrm{Lu}-\mathrm{NeoBOMB} 1\right)$ was injected as a $100-\mu \mathrm{L}$ bolus (3 nmol NeoBOMB1, associated with $11.1-22.2 \mathrm{MBq}$ of ${ }^{67} \mathrm{Ga}$ or ${ }^{111} \mathrm{In}$ and with $111 \mathrm{MBq}$ of ${ }^{177} \mathrm{Lu}$ ) in the tail vein of healthy male Swiss albino mice $(30 \pm 5 \mathrm{~g}$; NCSR "Demokritos" Animal House Facility). Mice were euthanized and blood $(0.5-1 \mathrm{~mL})$ collected at 5 min and, additionally for ${ }^{67} \mathrm{Ga}-\mathrm{NeoBOMB} 1$ and ${ }^{177} \mathrm{Lu}-\mathrm{NeoBOMB} 1$, at $30 \mathrm{~min}$ after injection was analyzed by high-performance liquid chromatography, as previously described $(21,23)$. The Symmetry Shield RP18 $(5 \mu \mathrm{m}, 3.9 \times 20 \mathrm{~mm})$ column was eluted at a flow rate of $1.0 \mathrm{~mL} / \mathrm{min}$ with the following gradient: $100 \%$ A to $90 \% \mathrm{~A}$ in $10 \mathrm{~min}$ and from $90 \% \mathrm{~A}$ to $60 \%$ for the next $60 \mathrm{~min}$; $\mathrm{A}=0.1 \%$ aqueous trifluoroacetic acid $(\mathrm{v} / \mathrm{v})$ and $\mathrm{B}=\mathrm{MeCN}$.

A bolus $(150 \mu \mathrm{L})$ containing a suspension of about $1.2 \times 10^{7}$ freshly harvested human PC-3 cells in saline was subcutaneously injected in the flanks of female severe combined immunodeficiency mice (15 \pm 3 g, 6 wk of age on arrival day; NCSR "Demokritos" Animal House Facility), and 3-4 wk later the mice developed wellpalpable tumors at the inoculation site $(80-150 \mathrm{mg})$. On the day of the experiment, a $\left[{ }^{67} \mathrm{Ga} /{ }^{111} \mathrm{In} /{ }^{177} \mathrm{Lu}\right]$ NeoBOMB1 bolus $(10 \mathrm{pmol}$ NeoBOMB1, associated with up to $74 \mathrm{kBq}$ of ${ }^{67} \mathrm{Ga}$ or ${ }^{111} \mathrm{In}$, or up to $370 \mathrm{kBq}$ of ${ }^{177} \mathrm{Lu}$, in $100 \mu \mathrm{L}$ of vehicle: saline/EtOH 9/1 v/v) was injected in the tail vein of mice. Biodistribution for the 1-, 4-, 24-, and 72 -h (for ${ }^{177} \mathrm{Lu}$ only) postinjection time intervals was conducted as previously described $(21,23)$; for in vivo GRPR blockade, animals of an additional 4-h group were coinjected with $\mathrm{Tyr}^{4}$-BBN (40 nmol). Biodistribution data were calculated as percentage injected dose per gram of tissue $(\% \mathrm{ID} / \mathrm{g})$ using the Microsoft Excel program and with the aid of suitable standards of the injected dose and represent mean $\pm \mathrm{SD}$, $n=4$. Statistical analysis was conducted using the unpaired 2-tailed Student $t$ test; $P$ values of less than 0.05 were considered statistically significant.

All animal experiments were performed in compliance with European and national regulations and after approval of protocols by national authorities. 


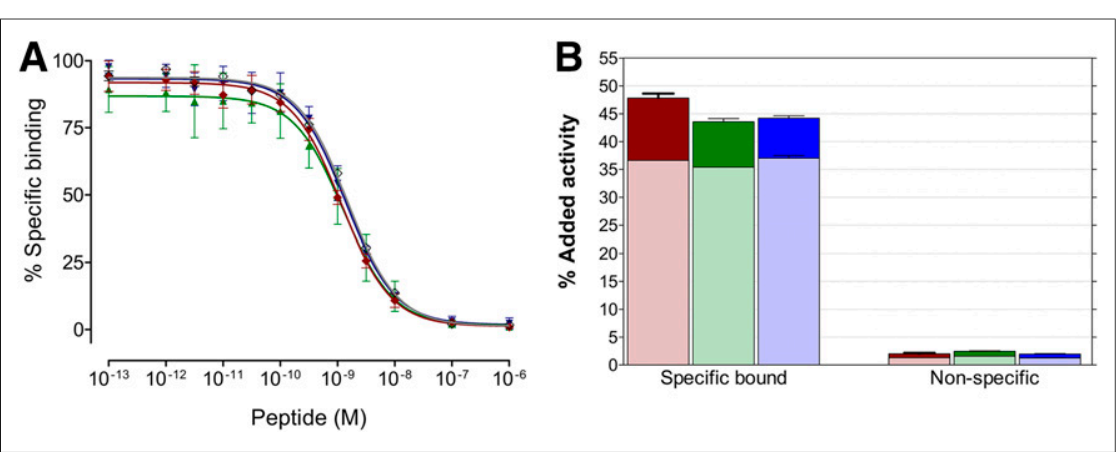

FIGURE 2. (A) Displacement of $\left[{ }^{125} \mid-\mathrm{Tyr}^{4}\right] \mathrm{BBN}$ from GRPR sites in PC-3 cell membranes by increasing concentrations of NeoBOMB1 (gray curve) $\left(\mathrm{IC}_{50}=1.49 \pm 0.07 \mathrm{nM}\right)$; ${ }^{\text {nat }} \mathrm{Ga}-\mathrm{NeoBOMB} 1$ (red curve) $\left(\mathrm{IC}_{50}=1.17 \pm 0.06 \mathrm{nM}\right)$; ${ }^{\text {nat }} \mathrm{In}-\mathrm{NeoBOMB} 1$ (green curve) $\left(\mathrm{IC}_{50}=1.28 \pm 0.14 \mathrm{nM}\right)$; ${ }^{\text {nat }} \mathrm{Lu}$ NeoBOMB1 (blue curve) $\left(\mathrm{IC}_{50}=1.38 \pm 0.09 \mathrm{nM}\right)$; and reference, Tyr ${ }^{4}-\mathrm{BBN}$ (curve not shown) $\left(\mathrm{IC}_{50}=1.33 \pm 0.09 \mathrm{nM}\right)$. Results represent mean $\mathrm{IC}_{50}$ values $\pm \mathrm{SD}, n=3$. (B) Internalized plus cell membrane-bound fractions in PC-3 cells shown for $\square \square \square,{ }^{67} \mathrm{Ga}-\mathrm{NeoBOMB} 1 ; \square / \square,{ }^{111} \mathrm{In}$ NeoBOMB1; and $\square \square,{ }^{177} \mathrm{Lu}-\mathrm{NeoBOMB} 1$, respectively $\left(1-\mathrm{h}\right.$ incubation at $\left.37^{\circ} \mathrm{C}\right)$; nonspecific values were determined in presence of $1 \mu \mathrm{M}$ BBN. Results represent average $I_{50}$ values $\pm S D, n=4$.

\section{Patients: Ethical and Regulatory Issues}

Four patients with prostate adenocarcinoma who were referred by their urologists underwent ${ }^{68} \mathrm{Ga}-\mathrm{NeoBOMB} 1 \mathrm{PET} / \mathrm{CT}$ at the Theranostics Research Center, Zentralklinik Bad Berka, Germany. The study protocol was approved by the Institutional Review Board, and all subjects signed a substantive written informed consent form. All patients were studied before by conventional imaging modalities (e.g., MRI, ${ }^{18} \mathrm{~F}$-choline PET, and ${ }^{99 \mathrm{~m} T \mathrm{Tc}-m e t h y l e n e}$ diphosphonate bone scanning). The decision to perform ${ }^{68} \mathrm{Ga}-\mathrm{NeoBOMB} 1 \mathrm{PET} /$ $\mathrm{CT}$ was based on the opinion of the referring urologists as the best choice for the patients' respective clinical conditions. ${ }^{68} \mathrm{Ga}-\mathrm{NeoBOMB} 1$ was administered in compliance with the German Medicinal Products Act (section 13, subsection 2b), the 1964 Declaration of Helsinki, and the responsible regulatory body (Government of Thuringia) and under the compassionate-use clause of the German Medicinal Products Act (Federal Institute for Drugs and Medical Devices, "Compassionate use" programs, http://www.bfarm.de/EN/Drugs/licensing/clinicalTrials/ compUse/_node). This pilot study was performed in accordance with the regulations of the German Federal Agency for Radiation Protection.

\section{${ }^{68}$ Ga-NeoBOMB1 PET/CT Imaging}

A dual-modality PET/CT tomograph (Biograph Duo; Siemens Medical Solutions) was used in the study. Patients were prepared and injected with 60-339 (median, 199.5, adapting the injected activity to the patient body weight) $\mathrm{MBq}$ of ${ }^{68} \mathrm{Ga}-\mathrm{NeoBOMB} 1$ before data acquisition, as detailed in the supplemental materials. Information on the applied imaging protocol, data acquisition, and reconstruction methods and image analysis are also reported therein.

\section{RESULTS}

\section{In Vitro Studies}

As shown in Figure 2A, NeoBOMB1 was able to displace $\left[{ }^{125} \mathrm{I}_{-} \mathrm{Tyr}^{4}\right] \mathrm{BBN}$ from GRPR sites in PC-3 membranes in a monophasic and dose-dependent manner. The calculated $\mathrm{IC}_{50}$ value of $1.49 \pm 0.07 \mathrm{nM}$ was found comparable to that of $\mathrm{Tyr}^{4}$-BBN reference $\left(\mathrm{IC}_{50}=1.33 \pm 0.09 \mathrm{nM}\right)$. Interestingly, incorporation of gallium, indium, or lutetium by the DOTA chelator did not negatively affect receptor affinity, with the corresponding $\mathrm{IC}_{50}$ values of $1.17 \pm 0.06$ $\mathrm{nM}$ found for ${ }^{\text {nat }} \mathrm{Ga}-\mathrm{NeoBOMB} 1,1.28 \pm$

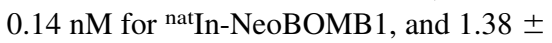
$0.09 \mathrm{nM}$ for ${ }^{\text {nat }} \mathrm{Lu}-\mathrm{NeoBOMB} 1$. Likewise, high and specific binding was observed for ${ }^{67} \mathrm{Ga}-\mathrm{NeoBOMB} 1(47.8 \% \pm 0.5 \%),{ }^{111} \mathrm{In}-$ NeoBOMB1 $(43.5 \% \pm 0.4 \%)$, and ${ }^{177} \mathrm{Lu}-$ NeoBOMB1 $(44.2 \% \pm 0.5 \%)$ in PC-3 cells after 1-h incubation at $37^{\circ} \mathrm{C}$ (nonspecific values $<3 \%$ ) (Fig. 2B). In all cases, most radioactivity was associated with the cell membrane, with a smaller portion $(\approx 10 \%)$ found within the cells, as expected for radioligands based on GRPR antagonists.

\section{Radioligand In Vivo Stability: Biodistribution in PC-3 Tumor-Bearing Mice}

As shown by the representative radiochromatograms in Figures 3A, 3B, and 3C, respectively, ${ }^{67} \mathrm{Ga}-\mathrm{NeoBOMB} 1,{ }^{111} \mathrm{In}-\mathrm{NeoBOMB} 1$, and ${ }^{177} \mathrm{Lu}-\mathrm{NeoBOMB} 1$ remained more than $95 \%$ intact in peripheral mouse blood at $5 \mathrm{~min}$ after injection. Furthermore, ${ }^{67} \mathrm{Ga}-\mathrm{NeoBOMB} 1$ and ${ }^{177} \mathrm{Lu}-\mathrm{NeoBOMB} 1$ were found more than $90 \%$ and $80 \%$ intact, respectively, in mouse circulation when further tested at $30 \mathrm{~min}$ after injection (Supplemental Fig. 3).

As shown in Figures 4A, 4B, and $4 \mathrm{C}$, respectively, ${ }^{67} \mathrm{Ga}-\mathrm{Neo}-$ BOMB1, ${ }^{111} \mathrm{In}-\mathrm{NeoBOMB} 1$, and ${ }^{177} \mathrm{Lu}-\mathrm{NeoBOMB} 1$ efficiently localized in the PC-3 xenografts in severe combined immunodeficiency mice $(30.7 \pm 3.9 \% \mathrm{ID} / \mathrm{g}, 28.6 \pm 6.0 \% \mathrm{ID} / \mathrm{g}$, and $42.4 \pm 5.0$ $\% \mathrm{ID} / \mathrm{g}$, respectively, at $4 \mathrm{~h}$ after injection). High uptake was observed also in mouse pancreas, a GRPR-rich organ. Coinjection with excess $\mathrm{Tyr}^{4}-\mathrm{BBN}$, a receptor agonist, was found to be partially effective to confirm specificity of uptake in the tumor and GRPRexpressing organs, as previously reported for GRPR antagonistbased radioligands $(17,23)$. On the other hand, coinjection with excess NeoBOMB1 was more than $90 \%$ effective to block GRPR sites in vivo (28). All analogs showed a fast blood clearance and were excreted predominantly via the kidneys; ${ }^{67} \mathrm{Ga}-\mathrm{NeoBOMB} 1$ showed somewhat elevated blood values at the initial time intervals
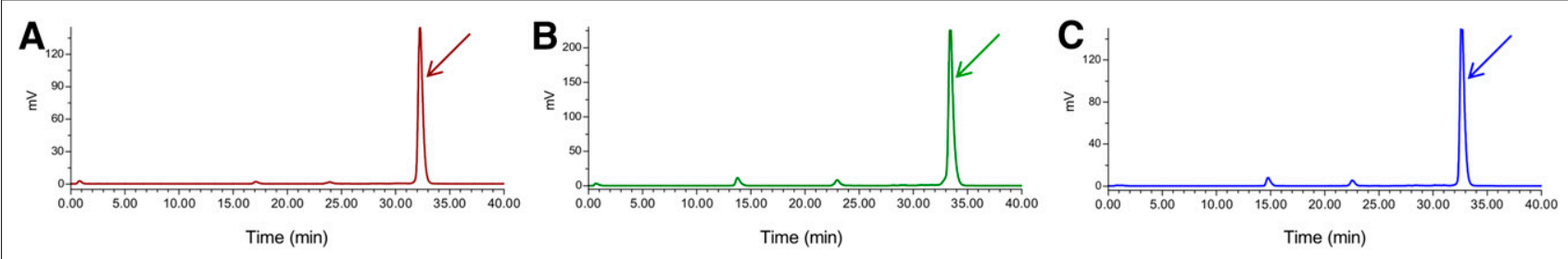

FIGURE 3. Representative radiochromatograms of blood samples collected 5 min after injection of ${ }^{67} \mathrm{Ga}-\mathrm{NeoBOMB1}$ (A), ${ }^{111} \mathrm{In}-\mathrm{NeoBOMB} 1$ (B), and ${ }^{177} \mathrm{Lu}-\mathrm{NeoBOMB} 1$ (C) in mice, showing more than $95 \%$ of radioligand detected intact; retention time of injected analog was determined by coinjection of radiopeptide in high-performance liquid chromatography column and is indicated by arrow. 


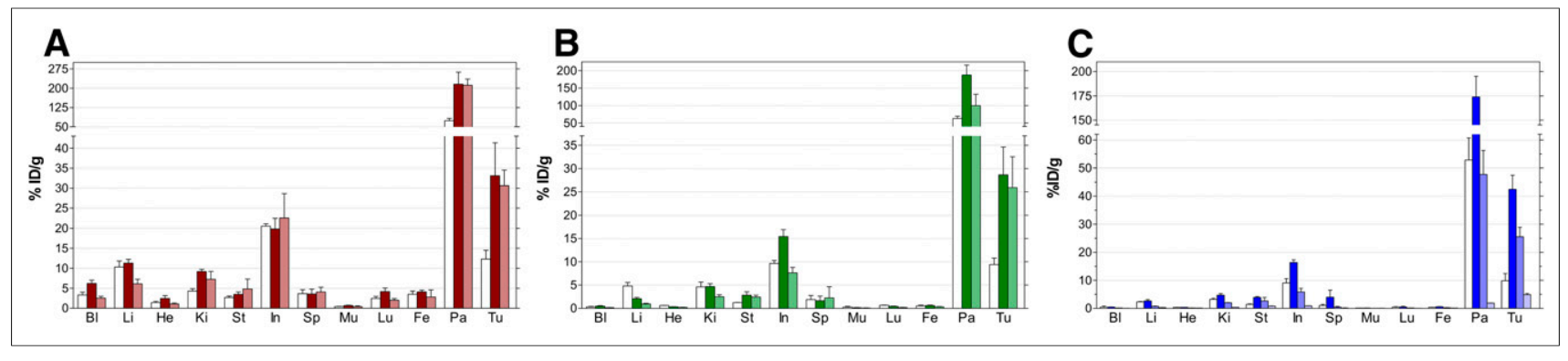

FIGURE 4. Biodistribution data of ${ }^{67} \mathrm{Ga}-\mathrm{NeoBOMB} 1 \square \mathrm{l}$ and $\square 4 \mathrm{~h}$ after injection) (A), ${ }^{111} \mathrm{In}-\mathrm{NeoBOMB} 1$ ( $\square 4$ and $\square 24 \mathrm{~h}$ after injection) (B), and ${ }^{177} \mathrm{Lu}-$ NeoBOMB1 ( $\square, \square$ 24, and $\square 72 \mathrm{~h}$ after injection) (C) in PC-3 tumor-bearing severe combined immunodeficiency mice expressed as $\% \mathrm{ID} / \mathrm{g}$ and representing mean $\pm \mathrm{SD}, n=4 ; \square$ in vivo GRPR blockade at $4 \mathrm{~h}$ after injection. $\mathrm{BI}=$ blood; $\mathrm{Fe}=\mathrm{femur} ; \mathrm{He}=\mathrm{heart} ; \mathrm{ln}=\mathrm{intestines;} \mathrm{Ki}=$ kidneys; $\mathrm{Li}=$ liver; $\mathrm{Lu}=$ lungs; $\mathrm{Mu}=$ muscle; $\mathrm{Pa}=$ pancreas; $\mathrm{Sp}=$ spleen; $\mathrm{St}=$ stomach; $\mathrm{Tu}=\mathrm{PC}-3$ xenograft.

as compared with its ${ }^{111} \mathrm{In}$ and ${ }^{177} \mathrm{Lu}$ counterparts. There was high tumor retention for ${ }^{67} \mathrm{Ga}-\mathrm{NeoBOMB} 1$ (serving as a ${ }^{68} \mathrm{Ga}-\mathrm{NeoBOMB} 1$ surrogate) between 1 and $4 \mathrm{~h}$ after injection and for ${ }^{111} \mathrm{In}-\mathrm{NeoBOMB} 1$ between 4 and $24 \mathrm{~h}$ after injection, both matching the respective radionuclide half-life. On the other hand, the uptake of ${ }^{177} \mathrm{Lu}-\mathrm{NeoBOMB} 1$ in the PC-3 xenografts, although declining between 4 and $24 \mathrm{~h}$, still remained at impressively high levels at $24 \mathrm{~h}$ after injection $(>25 \% \mathrm{ID} / \mathrm{g}$ at $24 \mathrm{~h}$ after injection). At later time points, tumor uptake declined further $(\approx 5 \% \mathrm{ID} / \mathrm{g}$ at $72 \mathrm{~h}$ after injection) but surpassed that in all other organs, including the GRPR-positive pancreas $(\approx 2 \% \mathrm{ID} / \mathrm{g}$ at $72 \mathrm{~h}$ after injection).

\section{PET/CT Results of ${ }^{68} \mathrm{Ga}-\mathrm{NeoBOMB1}$ in Prostate Cancer Patients}

Four prostate cancer patients from an ongoing proof-of-principle study who underwent ${ }^{68} \mathrm{Ga}-\mathrm{NeoBOMB} 1 \mathrm{PET} / \mathrm{CT}$ and with a complete dataset are presented herein first. The tracer was well tolerated by all subjects, and no side effect was registered from the administration of ${ }^{68} \mathrm{Ga}-\mathrm{NeoBOMB} 1$. A representative ${ }^{68} \mathrm{Ga}-\mathrm{NeoBOMB} 1$ PET/CT scan of a 69-y-old patient with primary bilateral prostate adenocarcinoma (initially classified cT1 [G3] cNx cMx; Gleason score, $8[4+4]$ ) and a prostate-specific antigen (PSA) of $6.33 \mathrm{ng} / \mathrm{mL}$ is presented in Figure 5, showing strong tracer uptake in the right and middle prostate lobes suggestive of multifocal prostate carcinoma. In Figure 6, multiple mediastinal, paraesophageal, abdominal, and pelvic lymph node metastases are strongly positive during ${ }^{68} \mathrm{Ga}-\mathrm{NeoBOMB} 1 \mathrm{PET} / \mathrm{CT}$ in a 65 -y-old patient. The patient was diagnosed 9 y before with prostate adenocarcinoma (classification pT3b [G3] pN1c M0; Gleason score, 7) and subsequently underwent radical prostatovesiculectomy with pelvic lymphadenectomy, intensitymodulated radiotherapy, and androgen-deprivation therapy. Because of an increasing PSA, restaging with ${ }^{68} \mathrm{Ga}-\mathrm{NeoBOMB} 1 \mathrm{PET} / \mathrm{CT}$ was indicated (PSA at $21.77 \mathrm{ng} / \mathrm{mL}$ on the date of scan). Two additional representative ${ }^{68} \mathrm{Ga}-\mathrm{NeoBOMB} 1 \mathrm{PET} / \mathrm{CT}$ scans are included and are further commented in Supplemental Figures 4 and 5.

\section{DISCUSSION}

In recent years, radiolabeled analogs of the frog tetradecapeptide BBN and its C-terminal BBN(6-14) fragment have been studied at length as potential candidates in the diagnosis and treatment of GRPR-positive human cancer, especially prostate and breast cancer $(7,8)$. In principle, this approach can be effective in targeting both primary and metastatic disease as long as a high density of GRPR expression in malignant lesions is preserved (1-4). According to the latest preclinical and clinical studies, radiolabeled GRPR antago- nists often outperform their agonist counterparts $(17,19,23)$. Furthermore, GRPR antagonists are deemed safer for human use than agonists. The latter induce GRPR activation after intravenous administration in humans, leading to strong adverse effects (16).

Previous experience in the management of neuroendocrine tumors with radiolabeled somatostatin analogs has highlighted the unparalleled strength of nuclear medicine to provide a theranostic approach in cancer (29-31). Ideally, a theranostic pair, represented by a peptideconjugate that can be labeled with either a diagnostic $\left({ }^{111} \mathrm{In} /{ }^{67} \mathrm{Ga}\right.$ for SPECT, or ${ }^{68} \mathrm{Ga}$ for PET) or a therapeutic radionuclide $\left({ }^{177} \mathrm{Lu}\right)$, is used for disease diagnosis, localization, staging, patient stratification, dosimetry, radiotherapy, and also therapeutic response monitoring (32). Both diagnostic and therapeutic radiopeptide should effectively target the GRPR-expressing lesions in

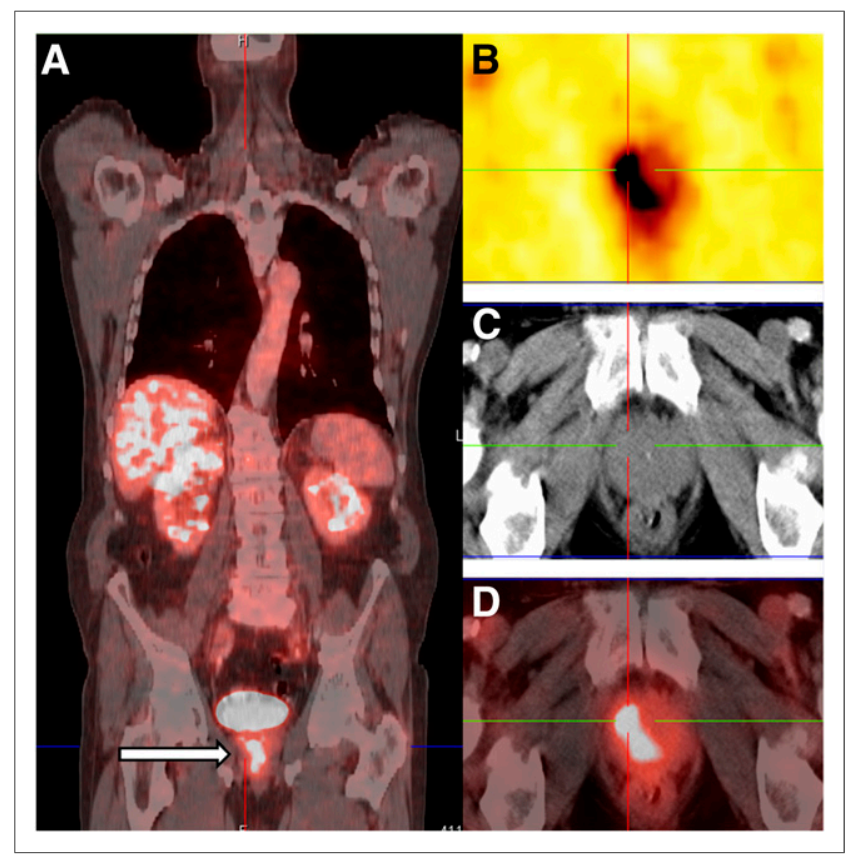

FIGURE 5. Detection of primary tumor (arrow and crossbars) in a 69$y$-old patient with prostate adenocarcinoma (bilateral) (Gleason score, $8[4+4]$ and PSA on day of scan, $6.33 \mathrm{ng} / \mathrm{m}) .{ }^{68} \mathrm{Ga}-\mathrm{NeoBOMB} 1 \mathrm{PET} / \mathrm{CT}$ fusion coronal (A), PET transverse $(B)$, corresponding CT transverse $(C)$, and fusion PET/CT (D) images are shown. Tracer uptake in right and middle prostate lobes is suggestive of multifocal prostate carcinoma. 


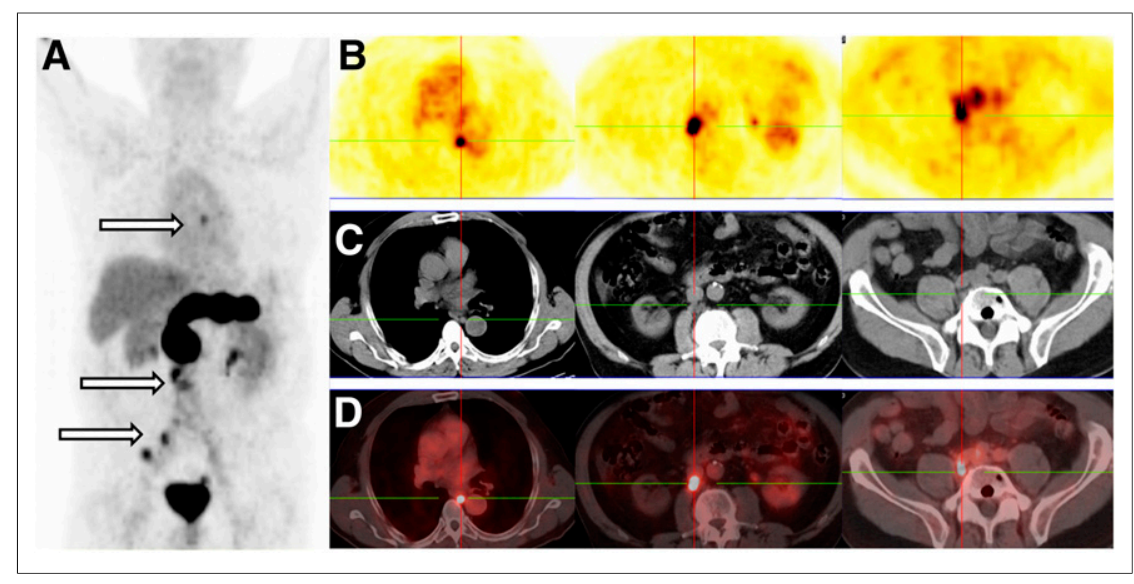

FIGURE 6. Patient with prostate adenocarcinoma, postradical prostatovesiculectomy with pelvic lymphadenectomy, intensity-modulated radiotherapy, and androgen-deprivation therapy (PSA on day of scan, $21.77 \mathrm{ng} / \mathrm{mL}$ ). ${ }^{68} \mathrm{Ga}-\mathrm{NeoBOMB} 1 \mathrm{PET}$ maximum-intensity projection (A), serial PET transverse $(B)$, corresponding CT transverse (C), and fusion PET/CT (D) images are shown. Multiple mediastinal, abdominal, paraesophageal, and pelvic lymph node metastases are indicated by arrows and crossbars.

vivo and, therefore, need to display similarly high receptor affinity and in vivo stability.

Following this rationale, we have recently introduced ${ }^{68} \mathrm{Ga}-\mathrm{SB} 3$ for PET imaging of prostate and breast cancer, effectively localizing in GRPR-positive lesions in mouse models and in patients (23). However, the respective therapeutic ${ }^{177} \mathrm{Lu}-\mathrm{SB} 3$ showed a receptor affinity inferior to and was less stable in vivo than its diagnostic counterpart ${ }^{68} \mathrm{Ga}-\mathrm{SB} 3$. Consequently, lower tumor uptake was achieved in mice, a handicap that could be reversed by in situ neutral endopeptidase inhibition with phosphoramidon (24). However, this promising approach, recently shown to improve the theranostic potential of other GRPR radioantagonists as well, has not yet been translated in humans (22).

In the present work, we introduce $\left[{ }^{68} \mathrm{Ga} /{ }^{111} \mathrm{In} /{ }^{177} \mathrm{Lu}\right]$ NeoBOMB 1 based on a previously well-characterized GRPR antagonist (26) and showing excellent qualities for PET or SPECT imaging as well as radionuclide therapy. First, NeoBOMB1 displayed single-digit nanomolar affinity for the human GRPR, even after incorporation of any of gallium, indium, or lutetium (Fig. 2A), thus appearing more suitable for theranostic applications than SB3. In line with affinity findings, the respective ${ }^{67} \mathrm{Ga}-\mathrm{NeoBOMB} 1,{ }^{111} \mathrm{In}-\mathrm{NeoBOMB} 1$, and ${ }^{177} \mathrm{Lu}-\mathrm{NeoBOMB} 1$ radioligands specifically bound to the cell membrane of PC-3 cells with comparably high efficacy and, as expected for receptor radioantagonists, showed minimal internalization efficacy. Of great interest is the fact, that all 3 radioligands were found more than $95 \%$ intact in peripheral mouse blood at $5 \mathrm{~min}$ after injection (Fig. 3) but also when tested at later time points $\left({ }^{67} \mathrm{Ga}-\mathrm{NeoBOMB} 1>90 \%\right.$ intact and ${ }^{177} \mathrm{Lu}-\mathrm{NeoBOMB} 1$ $80 \%$ intact at 30 min after injection; Supplemental Fig. 3), highlighting again the promising theranostic prospects of NeoBOMB1 as compared with SB3.

Taken together, these properties of receptor affinity, cell-binding efficacy, and metabolic stability seem to have led to excellent uptake of ${ }^{67} \mathrm{Ga}-\mathrm{NeoBOMB} 1,{ }^{111} \mathrm{In}-\mathrm{NeoBOMB} 1$, and ${ }^{177} \mathrm{Lu}-\mathrm{NeoBOMB} 1$ in the PC-3 tumors xenografted in mice (Fig. 4), further supporting the theranostic prospects of NeoBOMB1. Minor differences in biodistribution profiles can be attributed to differences in coordination chemistries with DOTA across radiometals, which, despite identical in vitro properties, slightly affected pharmacokinetic parameters in our mouse models. The high pancreatic uptake of the radioligands, although a result of high receptor affinity and in vivo stability, is rather undesirable for radiotherapy with ${ }^{177} \mathrm{Lu}-\mathrm{NeoBOMB} 1$. Nevertheless, it seems to decline more rapidly than the tumor uptake in our mouse model. By administering different NeoBOMB1 peptide doses in mice, it has been possible to impressively improve tumor-to-pancreas ratios and overall pharmacokinetics (28). On the other hand, interspecies differences of biologic profiles of GRPR-directed radioligands between mice and men have been reported $(33,34)$. Therefore, translational studies are warranted to establish the diagnostic (and also therapeutic) value of new GRPR radioantagonists.

For this purpose, ${ }^{68} \mathrm{Ga}-\mathrm{NeoBOMB} 1$ has been tested in a first-in-man study in 4 prostate cancer patients applying PET/CT. First, the excellent tolerability of NeoBOMB1 in men is a valuable asset for future GRPRtargeted radionuclide therapy options. Furthermore, the new tracer strongly localized in primary prostate-confined disease but also in multimetastatic foci during disease spread, as seen in the representative scans in Figures 5 and 6, respectively. Impressively, ${ }^{68} \mathrm{Ga}-$ NeoBOMB1 uptake was evident in a liver micrometastasis not visualized on the arterial phase of CT but later confirmed on followup angiography (Supplemental Fig. 4). ${ }^{68} \mathrm{Ga}-\mathrm{NeoBOMB} 1$ was able to detect lymph node metastases down to $5 \mathrm{~mm}$ in size, normally considered negative on conventional imaging, overall exhibiting a high diagnostic sensitivity. Of particular interest is the localization ability of ${ }^{68} \mathrm{Ga}-\mathrm{NeoBOMB} 1$ in osseous metastases (Supplemental Fig. 5), a finding requiring further investigation in a bigger cohort of patients. Previous reports have demonstrated the high upregulation of GRPR in well-differentiated prostate carcinoma, with the expression density declining in more advanced stages of the disease (1-3). Indeed, excellent outcome in therapy-naïve patients has recently been established with ${ }^{68} \mathrm{Ga}-\mathrm{SB} 3$ and PET/CT $(35,36)$. However, existing experience with ${ }^{68} \mathrm{Ga}-\mathrm{SB} 3$ (23) and the BBN-based ${ }^{99 \mathrm{~m}} \mathrm{Tc}-\mathrm{DB} 4$ tracer (37) indicated good tracer localization in several, but not all, bone metastases of prostate cancer.

On the other hand, prostate-specific membrane antigen represents an attractive target for small-size inhibitors in patients with advanced and less-differentiated disease, but less in early stages of prostate cancer (38). The clinical implications of prostate-specific membrane antigen and GRPR expression at different disease stages are not fully understood thus far, and further clinical studies are warranted. In a recent direct clinical comparison of a prostate-specific membrane antigen- and GRPR-directed ${ }^{68} \mathrm{Ga}$-labeled probe in 7 prostate cancer patients, the authors suggested that personalizing biomarker assessments are to be conceived in the future for patients with prostate cancer (39).

\section{CONCLUSION}

Theranostic approaches for GRPR-expressing human tumors, such as prostate and breast cancer, are becoming realistic with the advent of new-generation radiopeptides based on GRPR antagonists. In addition to higher biosafety, the new GRPR radioantagonists most often exhibit potent targeting of tumor lesions and 
attractive pharmacokinetics in animal models and patients. We herein introduce NeoBOMB1 and the $\left[{ }^{67 / 68} \mathrm{Ga} /{ }^{111} \mathrm{In} /{ }^{177} \mathrm{Lu}\right] \mathrm{NeoBOMB} 1$ radiopeptides, showing a remarkably preserved GRPR affinity and cell binding, high in vivo stability, and an ability to target prostate cancer xenografts in mice independent of radiometal used. These features highlight the theranostic prospects of NeoBOMB1. Firstin-man results with ${ }^{68} \mathrm{Ga}-\mathrm{NeoBOMB} 1 \mathrm{PET} / \mathrm{CT}$ in prostate cancer patients revealed the translational strength of the new tracer. Ongoing preclinical and clinical studies aim to investigate the true theranostic value of NeoBOMB1 in nuclear oncology.

\section{DISCLOSURE}

No potential conflict of interest relevant to this article was reported.

\section{REFERENCES}

1. Markwalder R, Reubi JC. Gastrin-releasing peptide receptors in the human prostate: relation to neoplastic transformation. Cancer Res. 1999;59:1152-1159.

2. Körner M, Waser B, Rehmann R, Reubi JC. Early over-expression of GRP receptors in prostatic carcinogenesis. Prostate. 2014;74:217-224.

3. Beer M, Montani M, Gerhardt J, et al. Profiling gastrin-releasing peptide receptor in prostate tissues: clinical implications and molecular correlates. Prostate. 2012;72:318-325.

4. Gugger M, Reubi JC. Gastrin-releasing peptide receptors in non-neoplastic and neoplastic human breast. Am J Pathol. 1999;155:2067-2076.

5. Reubi C, Gugger M, Waser B. Co-expressed peptide receptors in breast cancer as a molecular basis for in vivo multireceptor tumour targeting. Eur J Nucl Med Mol Imaging. 2002;29:855-862.

6. Halmos G, Wittliff JL, Schally AV. Characterization of bombesin/gastrin-releasing peptide receptors in human breast cancer and their relationship to steroid receptor expression. Cancer Res. 1995;55:280-287.

7. Maina T, Nock B, Mather S. Targeting prostate cancer with radiolabelled bombesins. Cancer Imaging. 2006;6:153-157.

8. Yu Z, Ananias HJ, Carlucci G, et al. An update of radiolabeled bombesin analogs for gastrin-releasing peptide receptor targeting. Curr Pharm Des. 2013;19:3329-3341.

9. Maddalena ME, Fox J, Chen J, et al. ${ }^{177} \mathrm{Lu}-\mathrm{AMBA}$ biodistribution, radiotherapeutic efficacy, imaging, and autoradiography in prostate cancer models with low GRP-R expression. J Nucl Med. 2009;50:2017-2024.

10. Nock BA, Nikolopoulou A, Galanis A, et al. Potent bombesin-like peptides for GRP-receptor targeting of tumors with ${ }^{99 \mathrm{mTc}}$ : a preclinical study. J Med Chem. 2005;48:100-110.

11. Zhang H, Schuhmacher J, Waser B, et al. DOTA-PESIN, a DOTA-conjugated bombesin derivative designed for the imaging and targeted radionuclide treatment of bombesin receptor-positive tumours. Eur J Nucl Med Mol Imaging. 2007;34:1198-1208.

12. Breeman WA, De Jong M, Bernard BF, et al. Pre-clinical evaluation of $\left[{ }^{111} \mathrm{In}-\right.$ DTPA-Pro $\left.{ }^{1}, \mathrm{Tyr}^{4}\right]$ bombesin, a new radioligand for bombesin-receptor scintigraphy. Int J Cancer. 1999;83:657-663.

13. Nock BA, Cescato R, Ketani E, Waser B, Reubi JC, Maina T. [ ${ }^{99 m}$ Tc]demomedin $\mathrm{C}$, a radioligand based on human gastrin releasing peptide(18-27): synthesis and preclinical evaluation in gastrin releasing Peptide receptor-expressing models. $J$ Med Chem. 2012;55:8364-8374.

14. Marsouvanidis PJ, Maina T, Sallegger W, Krenning EP, de Jong M, Nock BA. ${ }^{99 \mathrm{~m}} \mathrm{Tc}$ radiotracers based on human $\mathrm{GRP}(18-27)$ : synthesis and comparative evaluation. J Nucl Med. 2013;54:1797-1803.

15. Marsouvanidis PJ, Maina T, Sallegger W, Krenning EP, de Jong M, Nock BA. Tumor diagnosis with new ${ }^{111}$ In-radioligands based on truncated human gastrin releasing peptide sequences: synthesis and preclinical comparison. J Med Chem. 2013;56:8579-8587.

16. Bodei L, Ferrari M, Nunn A, et al. ${ }^{177} \mathrm{Lu}-\mathrm{AMBA}$ bombesin analogue in hormone refractory prostate cancer patients: a phase I escalation study with single-cycle administrations. Eur J Nucl Med Mol Imaging. 2007;34(suppl 2):S221.
17. Cescato R, Maina T, Nock B, et al. Bombesin receptor antagonists may be preferable to agonists for tumor targeting. J Nucl Med. 2008;49:318-326.

18. Nock B, Nikolopoulou A, Chiotellis E, et al. [ $\left.{ }^{99 \mathrm{~m}} \mathrm{Tc}\right]$ demobesin 1, a novel potent bombesin analogue for GRP receptor-targeted tumour imaging. Eur J Nucl Med Mol Imaging. 2003;30:247-258.

19. Wieser G, Mansi R, Grosu AL, et al. Positron emission tomography (PET) imaging of prostate cancer with a gastrin releasing peptide receptor antagonist: from mice to men. Theranostics. 2014;4:412-419.

20. Mansi R, Abiraj K, Wang X, et al. Evaluation of three different families of bombesin receptor radioantagonists for targeted imaging and therapy of gastrin releasing peptide receptor (GRP-R) positive tumors. J Med Chem. 2015;58:682-691.

21. Marsouvanidis PJ, Nock BA, Hajjaj B, et al. Gastrin releasing peptide receptordirected radioligands based on a bombesin antagonist: synthesis, ${ }^{111}$ In-labeling, and preclinical profile. J Med Chem. 2013;56:2374-2384.

22. Chatalic KL, Konijnenberg M, Nonnekens J, et al. In vivo stabilization of a gastrin-releasing peptide receptor antagonist enhances PET imaging and radionuclide therapy of prostate cancer in preclinical studies. Theranostics. 2016;6: 104-117.

23. Maina T, Bergsma H, Kulkarni HR, et al. Preclinical and first clinical experience with the gastrin-releasing peptide receptor-antagonist $\left[{ }^{68} \mathrm{Ga}\right] \mathrm{SB} 3$ and PET/CT. Eur J Nucl Med Mol Imaging. 2016;43:964-973.

24. Lymperis E, Maina T, Kaloudi A, Krenning EP, de Jong M, Nock BA. Transient in vivo NEP inhibition enhances the theranostic potential of the new GRPRantagonist $\left[{ }^{111} \mathrm{In} /{ }^{177} \mathrm{Lu}\right] \mathrm{SB}$. Eur J Nucl Med Mol Imaging. 2014;41(suppl 2): S319.

25. Mansi R, Wang X, Forrer F, et al. Development of a potent DOTA-conjugated bombesin antagonist for targeting GRPr-positive tumours. Eur J Nucl Med Mol Imaging. 2011;38:97-107.

26. Heimbrook DC, Saari WS, Balishin NL, et al. Gastrin releasing peptide antagonists with improved potency and stability. J Med Chem. 1991;34:2102-2107.

27. Reile H, Armatis PE, Schally AV. Characterization of high-affinity receptors for bombesin/gastrin releasing peptide on the human prostate cancer cell lines PC-3 and DU-145: internalization of receptor bound ${ }^{125} \mathrm{I}-\left[\mathrm{Tyr}^{4}\right]$ bombesin by tumor cells. Prostate. 1994;25:29-38.

28. Dalm SU, Bakker I, de Blois E, et al. NeoBOMB1, a novel radiolabeled GRPR antagonist for theranostic use. J Nucl Med. September 8, 2016 [Epub ahead of print].

29. Oberg K. Molecular imaging radiotherapy: theranostics for personalized patient management of neuroendocrine tumors (NETs). Theranostics. 2012;2:448-458.

30. Baum RP, Kulkarni HR, Carreras C. Peptides and receptors in image-guided therapy: theranostics for neuroendocrine neoplasms. Semin Nucl Med. 2012;42: 190-207.

31. Fani M, Maecke HR, Okarvi SM. Radiolabeled peptides: valuable tools for the detection and treatment of cancer. Theranostics. 2012;2:481-501.

32. de Jong M, Breeman WA, Kwekkeboom DJ, Valkema R, Krenning EP. Tumor imaging and therapy using radiolabeled somatostatin analogues. Acc Chem Res. 2009;42:873-880.

33. Maina T, Nock BA, Zhang H, et al. Species differences of bombesin analog interactions with GRP-R define the choice of animal models in the development of GRP-R-targeting drugs. J Nucl Med. 2005;46:823-830.

34. de Jong M, Maina T. Of mice and humans: are they the same?-Implications in cancer translational research. J Nucl Med. 2010;51:501-504.

35. Bakker IL, Fröberg A, Busstra M, et al. A novel gallium-68-labelled GRP receptor antagonist, $\left[{ }^{68} \mathrm{Ga}\right]$ sarabesin 3 , for prostate cancer imaging: first results in therapy naïve primary patients. Eur J Nucl Med Mol Imaging. 2015;42(suppl 1): S125.

36. Bakker IL, Fröberg A, Busstra M, et al. PET imaging of therapy-naïve primary prostate cancer patients using the GRPr-targeting ligand sarabesin 3 [abstract]. Eur Urol Suppl. 2016;15:567.

37. Mather SJ, Nock BA, Maina T, et al. GRP receptor imaging of prostate cancer using [99m Tc]Demobesin 4: a first-in-man study. Mol Imaging Biol. 2014;16:888-895.

38. Ristau BT, O'Keefe DS, Bacich DJ. The prostate-specific membrane antigen: lessons and current clinical implications from 20 years of research. Urol Oncol. 2014;32:272-279.

39. Minamimoto R, Hancock S, Schneider B, et al. Pilot comparison of ${ }^{68} \mathrm{Ga}-\mathrm{RM} 2$ PET and ${ }^{68} \mathrm{Ga}$-PSMA PET in patients with biochemically recurrent prostate cancer. J Nucl Med. 2016;57:557-562. 